\title{
Pulmonary impairment in rheumatoid arthritis
}

I mpairment of the respiratory system in rheumatoid arthritis (RA) is an important cause of morbidity and mortality. ${ }^{1}$ The manifestations can vary and include interstitial pulmonary infiltrates, pleural impairment, single or multiple pulmonary nodules, disorders of the central and peripheral airways, vascular bed diseases, drug-induced pulmonary toxicity, and secondary infections..$^{1-3}$ Among all those possibilities, interstitial pulmonary infiltrates gain importance due to their greater prevalence and possible progression to end-stage pulmonary fibrosis with respiratory failure. Usually, pulmonary impairment in RA occurs in patients with well-established articular disease. ${ }^{1-3}$ However, pulmonary infiltrates can be the first manifestation of the disease in up to $20 \%$ of the cases. ${ }^{1}$

Much of what is known about pulmonary impairment in RA has been identified in recent years, mainly after the appearance of more sophisticated radiological techniques, such as chest high-resolution computed tomography obtained with advanced technology devices. Studies using that technique have shown pulmonary infiltrates in $20 \%$ to $63 \%$ of the patients studied. In addition, such findings can be often seen in asymptomatic patients with respiratory disorders, who have been recently diagnosed with rheumatic disease. ${ }^{4}$ In such situation, ground glass opacities and subpleural septal thickening predominate, usually of limited extent.

In the present number of the Revista Brasileira de Reumatologia, Skare et al. ${ }^{5}$ studied the presence of tomographic changes in a sample of 71 patients with RA, followed up in specialized clinics and outpatient clinics of the state of Paraná. The prevalence of tomographic changes was 55\%, with predominance of the reticular pattern, although the presence of cough and dyspnea was equally low, both in the group with changes and in that without them. In addition, a significant association of the presence of nodular and reticular lesions with the longer duration of disease has also been reported. Such results are in accordance with data previously published in the international literature, and indicate that the radiological detection of pulmonary impairment in RA is an increasingly common reality in the daily clinical practice also in Brazil. The lack of a significant association of the presence of pulmonary impairment with the male sex, smoking habit, or use of drugs potentially toxic to the lungs, such as methotrexate, which have been previously described as risk factors, can be justified by the relatively small number of patients in the case series.

It is worth noting that, from the histological point of view, pulmonary impairment in RA can be very heterogeneous, and different patterns of interstitial pneumonitis associate with different prognosis. ${ }^{6}$ Thus, the usual interstitial pneumonia pattern shows minimal chances of responding to corticosteroids and immunosuppressant agents, while the cellular non-specific interstitial pneumonia and organizing pneumonia usually have good prognosis. However, surgical pulmonary biopsies should not be routinely indicated in patients with collagen-vascular diseases and pulmonary impairment. Thus, the presence on chest tomography of extensive areas of ground-glass opacity or condensations is believed to indicate greater chances of responding to the immunosuppressant treatment, while typical radiological patterns of usual interstitial pneumonia, with peripheral septal thickening, extensive areas of honeycombing, and traction bronchiectasis, indicate poor prognosis. ${ }^{1,2,6}$

Serial pulmonary function tests in such patients are as important as the imaging exams. In one study, the only element capable of predicting the progression of pulmonary interstitial disease in patients with RA, in the next two years, was an initial carbon monoxide diffusion value lower than $54 \%$ of the expected. ${ }^{7}$

Although our capacity of detecting pulmonary infiltrates associated with RA has increased enormously, innumerous doubts relating to the ideal management of such conditions still remain. The role of the natural history of mild infiltrates, particularly ground-glass opacities, in asymptomatic patients has not been clarified. The actual role of the immunosuppressant treatment is yet to be completely elucidated, even in patients with more advanced pulmonary disease. Thus, the establishment of absolute recommendations for the management of such conditions is difficult. Currently, a set of general principles based mainly on common sense and on our own clinical experience can help in the decision making process by clinicians caring for such patients: 
- Patients with RA and no respiratory symptoms should undergo at least one chest radiography at the beginning of their follow-up.

- Patients with RA and no respiratory symptoms, with normal initial chest radiography, should undergo at least one chest radiography annually.

- Patients with RA and respiratory symptoms, or with radiological changes detected on chest radiography, should undergo complete spirometry and high-resolution computed tomography.

- Patients with RA and respiratory symptoms, with radiological changes or pulmonary function changes, should be jointly managed by one rheumatologist and one pulmonologist.

- Treatment with corticosteroids and immunosuppressants, such as cyclophosphamide or azathioprine, should be restricted to individuals whose symptoms can be attributed to interstitial infiltrates, who show well-characterized spirometric changes, or who evidence progressive decline in pulmonary function parameters on serial tests.

- The administration route, either oral or intravenous, the dose of immunosuppressants, and the duration of treatment should be based on the severity of the initial clinical-radiological-functional findings and on the responses observed.
- Currently, there is no sufficient evidence to indicate the treatment of pulmonary infiltrates associated with RA and leflunomide or biologics.

- In patients with pulmonary infiltrates of recent onset, the possibility of infections or drug-induced pulmonary toxicity, especially methotrexate, should be excluded.

- Surgical pulmonary biopsies can be indicated when diagnostic doubts persist, or when the evolution differs from that expected based on the tomographic patterns initially observed.

- In selected cases of patients under the age of 65 years, with advanced pulmonary disease, no adequate response to the treatment instituted, and no significant comorbidities, the possibility of pulmonary transplantation should be considered.

In conclusion, it is clear that the pulmonary impairment in RA is a complex subject, yet to be clearly understood. Further research, such as that by the group of Curitiba, is required ${ }^{5,8}$ and very welcome, so that the disease can be better known and its management better conducted.

José Antônio Baddini Martinez

Associated Professor Division of Pulmonology; Department of Internal Medicine Medical School of Ribeirão Preto - Universidade de São Paulo 


\section{REFERENCES}

\section{REFERÊNCIAS}

1. Ozerkis-Antin D, Evans J, Rubinowitz A, Horner RJ, Matthay RA. Pulmonary manifestations of rheumatoid arthritis. Clin Chest Med 2010; 31(3):451-78.

2. Tanaka N, Kim JS, Newell JD, Brown KK, Cool CD, Meehan R et al. Rheumatoid arthritis-related lung diseases: CT findings. Radiology 2004; 232(1):81-91.

3. Gabbay E, Tarala R, Will R, Carroll G, Adler B, Cameron D et al. Interstitial lung disease in recent onset rheumatoid arthritis. Am J Respir Crit Care Med 1997; 156(2 Pt 1):528-35.

4. Metafratzi ZM, Georgiadis AN, Ioannidou CV, Alamanos $\mathrm{Y}$, Vassiliou MP, Zikou AK et al. Pulmonary involvement in patients with early rheumatoid arthritis. Scand J Rheumatol 2007; 36(5):338-44.

5. Skare TL, Nakano I, Escuissiato DL, Batistetti, R, Rodrigues TO, Silva MB. Alterações de tomografia pulmonar de alta resolução em pacientes com artrite reumatoide e suas associações com variáveis clínicas, demográficas, sorológicas e terapêuticas. Rev Bras Reumatol 2011; 51(4):323-37.

6. Lee HK, Kim DS, Yoo B, Seo JB, Rho JY, Colby TV et al. Histopathologic pattern and clinical features of rheumatoid arthritis-associated interstitial lung disease. Chest 2005; 127(6):2019-27.

7. Dawson JK, Fewins HE, Desmond J, Lynch MP, Graham DR. Predictors of progression of HRCT diagnosed fibrosing alveolitis in patients with rheumatoid arthritis. Ann Rheum Dis 2002; 61(6):517-21

8. Mota LM, Cruz BA, Brenol CV, Pereira IA, Fronza LSR, Bertolo MB et al. 2011 Consensus of the Brazilian Society of Rheumatology for diagnosis and early assessment of rheumatoid arthritis. Rev Bras Reumatol 2011; 51(3):199-219. 